\title{
Integration of Business and Industrial Knowledge on Services to Set Trusted Business Communities of Organisations
}

\author{
Frédérique Biennier, Régis Aubry, and Mathieu Maranzana \\ INSA Lyon, LIESP, 69621 Villeurbanne Cedex, France \\ \{frederique.biennier, regis.aubry, mathieu.maranzana\} ainsa-lyon. fr
}

\begin{abstract}
To fit the globalized economical environment, more and more SMEs have to develop networked and collaborative strategies. Such collaborative networks are mostly based on trusted and well known networks. At the international level, the European Union promotes clearly internet of services based solutions to support innovative business communities of organisations. The results accumulated by various projects provide a consistent environment (including methods, design tools and ESB-based developments) to support, at a technological level, Business Service oriented organizations. Nevertheless, these visions are mostly technology oriented and lack of taking into account industrial characteristics. To overcome this limit, we aim at integrating industrial functional and non functional business and industrial properties (including management strategy, quality, process maturity...) in service registries. This improves service selection and composition to set consistent dynamic collaborative organizations based on trusted business communities of organisations.
\end{abstract}

Keywords: Service Oriented Enterprise, non functional properties, industrial services, business governance, trust community of organisations.

\section{Introduction}

The increased calls for mass customization and for integrating sustainable constraints in production organization raised interest in product/service management, leading to the emergence of ecosystem of services allowing to build dynamically "productservice chains" to anticipate consumer needs. These new business conditions induce significant organizational changes within enterprises, such as focusing on their core business and developing new collaborative strategies, calling for agility and new business strategies [9]. Setting collaborative processes between enterprises and especially among SMEs is a promising approach to industrial competitiveness and is expected to generate substantial savings, expand market positions or develop new opportunities for the participants. Within inter-firm collaborations, participants undertake joint business activities that may include co-design, co-marketing, co-production, co-development, sharing resources. This involves (1) reorganizing the enterprise according to the business services it can propose and publish, (2) being able to select the convenient partners, and (3) being able to orchestrate its activity according to these business services among different business areas to provide an end-to-end business 
value-added service chain to the customer. By this way, industrial networks can emerge leading to new business opportunities and new management rules. Nevertheless, the development of large-scale collaborative organizations is by now limited due to geographic constraints or lack of trust between partners.

Such distributed and collaborative organizations make heavy use of ICT technologies [4] requiring more and more IT inter-operability and agility. Unfortunately, as different software environments are used to support different business areas, the global information system often lacks consistency, interoperability and agility. Moreover, web-economy oriented collaborative frameworks are devoted to commercial relationships, and do not integrate any industrial constraints nor business related knowledge. This can lead to inconsistent industrial collaborative organization, decreasing the global efficiency and increasing waste rate due to non value-added activities.

To overcome these limits, business service ecosystems have to integrate various constraints (as industrial ones) to define extended business service models, paying a particular attention on "functional" properties (describing what the service can do) and "non functional" properties (as security, quality of service, industrial reliability...) in order to improve services discovery and CNO enactment. In this paper, after describing the context and the state of the art (section 2), we introduce our industrial service architecture (section 3), focusing mostly on the governance tools to support trusted-community of organisations management features.

\section{Context and State of the Art}

Developing large scale networked and collaborative strategies involves improving the potential partner selection process and increasing the IT support agility and interoperability. At the international level, the European Union clearly promotes solutions to support and favour innovative business networks on the basis of an internet of services in the FP7 work program. Nevertheless, this vision focuses mostly on the IT support stakes (syntactic and semantic interoperability, collaborative work space organization, process formalization...) but does not take into account neither the industrial constraints (production or purchase management, industrial process organization...) nor the way partners are identified and selected (face to face contact, cooptation...). Moreover, integrating sustainable constraints involves focusing on the "delivered product" lifecycle, adding value-added services, leading to ProductService Systems. These product-Service Systems have been pointed out since the beginning of the 2000s [11] and have been classified by [20] depending on the tangible/intangible parts (from a product oriented organisation to a result oriented organisation). These different models lead to a product-service taxonomy based on the product identification and ownership but they lack taking into account the global product service supply-chain organization, and the way partners can be selected. Only few works pay attention on the way services are created, selected and composed [15] and collaborations are set to support the global product life-cycle [14]. Nevertheless, this service-based approach is limited by the way partners can be discovered and selected.

To improve at a large-scale partner discovery and selection, services must be published widely. This is partly done at the IT level by enriching SOA-based registries with semantic annotation that are used to discover more efficiently potential partners 
fitting the requirements. Nevertheless, discovering services is not enough to set a collaborative organization: a particular attention must be paid on trust level between partners [8]. Different criteria can be used to define this trust level: objective value of non functional properties (as cost, delay...) related to the service [18], security policy implementation [5], a mix of criteria including human relationships [10], or other cultural criteria [6]... All these approaches bring to light that non functional properties must be described and managed. As proposed in different enterprises Architecture Level, supervision and governance functions are split between the business and the technological levels. Works developed at a technological service level entail a dynamic monitoring system, taking into account several Service Level Agreements (SLAs). As several services, suppliers and technologies are involved in a complex service chain, the global management is rather complex. On one hand it requires online computing of Quality of Service (QoS) levels. On the other hand, Business Activity Monitoring systems lack of connections between the collaborative process organization, performance indicators and SLAs. To overcome this limit, the OASIS WS-Quality Management proposal [12] establishes a first link between these basic SLAs and Business Level Agreements (BLA) but it lacks of defining strategies to combine agreements. This requires setting a Business Level Agreement (BLA) composition mechanism and a BLA based supervision console to improve the agreement negotiation process [13].

To overcome these limits (namely lack of industrial constraints in service definition and limited partners selection), hybrid approaches mixing industrial engineering, IT components and virtual networks' management skills must be set.

\section{Industrial Services Registry Organization}

To meet the large-scale collaborative organization challenge, we propose to organize an industrial service infrastructure taking advantage of the cloud technology development and extending the breeding virtual organization proposed by [1]. Instead of setting groups of trusted partners waiting for a collaboration opportunity, we propose to organise an open publication of industrial services and second to support an open cooptation mechanism thanks to a multi-level governance toolsets in order to manage trust-oriented parameters. Each potential partner sets and manages its own registry to publish its offers / demands. Identified business communities of organisations (breeding virtual organisation) also set their own registries and / or federate their members own registries. A distributed federation manager is implemented on each node managing a registry (1) to discover other registries, and (2) manage trust relationships within new potential partners (fig 1). This industrial service infrastructure relies on two challenges (1) the industrial multi-dimensional description and (2) the organization of a distributed governance environment able to manage the different parameters used to establish trusted relationships.

Our industrial Semantic Web Service takes into account the industrial functional properties (describing the "business related" competencies) and non functional properties (describing the industrial quality of service as well as security). By this way, a qualitative management process can be supported [7]. This business dimension goes beyond semantic annotation of services. It describes the operational part, the business rules and the organizational constraints related to services. Each service is described according to 2 main dimensions: 


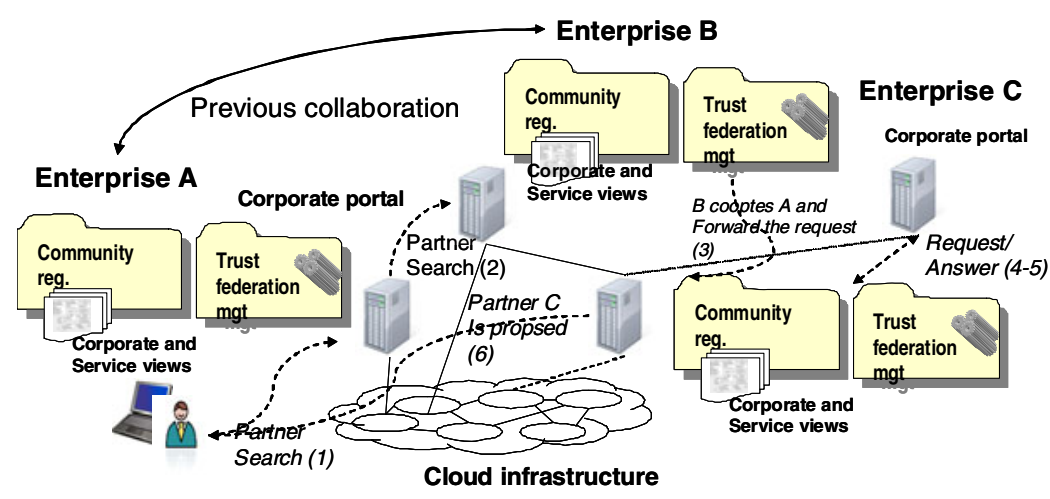

Fig. 1. Industrial registry organization

Each partner manages its own service registry. The trust federation manager is used to interconnect these registries, and manages cooptation rules. For example, A looks for a partner, due to a previous collaboration, B coopts A to its community of organisations so that A can discover enterprise $\mathrm{C}$.

- Corporate dimension: It is divided four axis:

o Partner administrative properties: it includes both partner identification and location information. This last information can be fruitfully used to improve the delivery process.

o Collaboration-oriented properties: it refers to other partners with whom collaborative organizations are/ have been sets. This can be seen either as "references" to be selected for a new collaborative organization or as basic network building mechanisms.

o Maturity property: it refers to the enterprise organization so that potential partners can identify if the process / service is well formalized, documented, and consequently can be associated to certification process. To the end, we use the Capability Maturity Model Integration classification first defined in the software development context and adapted to other production contexts including service environment [17].

o IT support properties: it describes optionally the current ICT tools and means that are commonly used by the partner. This information is used to manage the technological interoperability objective.

- Service dimension: it includes 2 axis:

○ Functional properties: It refers to product / service industrial description:

- Competencies description is related to business area and is detailed according to a specialized ontology in order to describe what is offered by the partner. It includes production machines and tools, material and product / service identification.

- Production strategy description : It refers to the Production management part of the ISA S95 ontology, this description is used to set a consistent industrial collaborative organization (depending on production management strategy and its related "configuration parameters"). 
o Non functional properties: They describe how the product / service could be achieved and are used to establish trusted relationships between partners. They includes different parameters (as security, process maturity, quality of service) describing for each parameter both a pledge part (what can be promised and integrated in a BLA) and a control part (in order to check if the pledge is fulfilled or not):

- Security properties: In order to fit the dynamic environment, different security policies are defined as semantic annotations referring to a perceived risk and counter-measures [16]. The convenient policy is selected according to the current context and is used to conclude the related Quality of protection agreement.

- Quality of Service properties: They refer to the service "environmental" interface, paying attention on the industrial performance indicator associated to the requested good (product and / or service). It includes (but it is not limited to):

- Reliability: Associated to a particular good, it assessesz the partner confidence of being able to deliver the good according to the request. This indicator is coupled to the monitoring system (so that experiences can be capitalized), storing different values: mean, standard deviation and current offer.

- Delay: It describes the potential delay necessary to provide the good and is also associated to different values: mean, standard deviation and current offer.

- Configuration ability: It defines if the good can be tuned according to given patterns or not.

- Adaptation level: It defines if the good production process can be adapted or not.

- Global quality: Based on business-area certification classification, it assesses the production quality and focuses on reporting abilities.

- Cost and financial characteristics: It includes current cost value, payment facilities...

- Sustainable growth characteristics: material certification, CO2 evaluation...

All these properties are defined as semantic annotation on the service. To overcome the limit due to the single reference ontology involved in SAWSDL, YASA4WSDL [3] refers to different ontologies within the annotations. By this way, we define different onologies related to the industrial service dimensions to enrich the service description with the convenient WSDL semantic annotation. This multiple description technique improves the semantic matching used to discover and select services fitting the best functional and non functional requirements.

Built upon the existing JONES platform, our industrial registry infrastructure is organized in a distributed way. This architecture allows us to take advantage of the semantic and service layer governance toolsets provided by PEtALS ${ }^{1}$ (SOA monitoring features),

${ }^{1}$ PEtALS is an open source ESB supported by the JONES platform. Documentation and downloads are available at: petals.ow2.org 
DRAGON $^{2}$ (distributed registry, SLA and contract management) and SemEUsE $^{3}$ (semantic registry, semantic probes and late binding features) to manage, discover, compose and monitor industrial services. It also allows establishing the related BLA and SLA thanks to adapted monitoring features [2]. Using the federation registry manager, this tool will be enriched to assess trust levels and control its evolution while exchanging information with other registries, taking advantage of our previous works in real-time system QoS management [19].

\section{Conclusion}

Due to increased customization in a globalized economy and to the development of "Service Oriented Products," enterprises have to adapt their organizational and business strategy, enhancing their own agility, reducing waste (non value-added activity) and focusing on their core-business. Setting collaborative processes between enterprises and especially among SMEs is a promising approach to industrial competitiveness, and is expected to generate substantial savings, expand market positions and / or develop new opportunities for the participants. To develop large-scale collaborative organization, we propose a distributed industrial service registry that enriches the SemEUsE architecture with different industry related ontologies and business level monitoring abilities.

Acknowledgments. This work has been partly supported by the ANR SemEUsE project under grant 2007TECLOG017 and by the Rhône-Alpes area council via the Cluster GOSPI SIMSYPROD project.

\section{References}

1. Afsarmanesh, H., Camarinha-Matos, L.M.: A framework for management of virtual organizations breeding environments. In: Proceedings of PRO-VE 2005 - Collaborative networks and their breeding environments, September 26-28, pp. 35-48. Springer, Valencia (2005)

2. Alhalabi, F., Narkoy, B., Aubry, R., Maranzana, M., Morel, L., Sourrouille, J.L.: Centralized vs decentralized QoS management policy. In: $3^{\text {rd }}$ International Conference on Information and Communication Technologies: From Theory to Applications (ICTTA 2008), April 7-11, pp. 1-6. IEEE Press, Los Alamitos (2008)

3. Chabeb, Y., Tata, S.: Yet Another Semantic Annotation for WSDL. In: IADIS International Conference WWW/Internet 2008, pp. 437-441 (2008)

4. DeVor, R., Graves, R., Mills, J.J.: Agile manufacturing research: accomplishments and opportunities. IIE Transactions 29, 813-823 (1997)

5. Garcia, D.G., Felgar de Toledo, M.B.: An approach for establishing trust relationships in the web service technology. Pervasive collaborative networks. In: Camarinha-Matos, L.M., Picard, W. (eds.) Proceedings of PRO-VE 2008, pp. 509-516 (2008)

${ }^{2}$ Dragon is an open source SOA governance toolset including a syntactic registry manager, a SLA manager and a policy manager. Information and downloads are available at: dragon.ow2.org

${ }^{3}$ SemEUsE is a semantic extension of PEtALS currently under development via the ANR $2007 \mathrm{TecLog} 017$ project. Information and demos are available at: www.semeuse.org 
6. Grudzewski, W.M., Hejduk, I.K., Wantuchowicz, M.: Cultural determinants of creating modern organizations - The role of trust. Pervasive collaborative networks. In: CamarinhaMatos, L.M., Picard, W. (eds.) Proceedings of PRO-VE 2008, pp. 323-332 (2008)

7. Karvonen, I., Ollus, M., Uoti, M.: Qualitative monitoring to support pro-active virtual organization management. Pervasive collaborative networks. In: Camarinha-Matos, L.M., Picard, W. (eds.) Proceedings of PRO-VE 2008, pp. 185-192 (2008)

8. Laaksonen, T., Kulmala, H.I.: Coordinating supplier relations: the role of interorganizational trust and interdependencies. Network-centric collaboration and supporting frameworks. In: Camarinha-Matos, L., Afsarmanesh, H., Ollus, M. (eds.) Proceedings of PROVE 2006, pp. 191-198 (2006)

9. Lee, H.L.: The Triple A Supply Chain. Harvard Business Review, 102-112 (October 2004)

10. Mezgar, I.: Trust building for enhancing collaboration in virtual organization. Networkcentric collaboration and supporting frameworks. In: Camarinha-Matos, L., Afsarmanesh, H., Ollus, M. (eds.) Proceedings of PRO-VE 2006, pp. 173-180 (2006)

11. Mont, O.: Product-service systems: panacea or myth? PhD Dissertation, Lund University, p. 25 (2004)

12. OASIS: Web Services Quality Model v1.0 (2007), http: / /www. oasis-open.org/ committees / download.php/26678/wsqm-ws_quality_model-wd-v1.0r04.doc

13. Oliveira, A.I., Camarinha-Matos, L.M., Pouly, M.: Agreement negotiation support in virtual organization creation. Pervasive collaborative networks. In: Camarinha-Matos, L.M., Picard, W. (eds.) Proceedings of PRO-VE 2008, pp. 107-118 (2008)

14. Salkari, L., Hytönen, H.: Challenges of lifecycle service business for virtual organizations. Network-centric collaboration and supporting frameworks. In: Camarinha-Matos, L., Afsarmanesh, H., Ollus, M. (eds.) Proceedings of PRO-VE 2006, pp. 443-452 (2006)

15. Schuh, G., Dirlenbach, H., Georgi, L.: Service development in virtual enterprises. Network-centric collaboration and supporting frameworks. In: Camarinha-Matos, L., Afsarmanesh, H., Ollus, M. (eds.) Proceedings of PRO-VE 2006, pp. 527-534 (2006)

16. Sliman, L., Biennier, F., Badr, Y.: A security policy framework for context-aware and user preferences in e-services. Journal of Systems Architecture Journal of Systems Architecture 55(4), 275-288 (2009)

17. Software Engineering Institute: CMMI for Services, version 1.2. Carnegie Mellon University Technical Report, February 2009. p. 545 (2009), http://www.sei.cmu.edu/ publications / documents / 09. reports / 09tr001.html

18. Urze, P.: Industrial networks trust bonds: a sociological perspective. Network-centric collaboration and supporting frameworks. In: Camarinha-Matos, L., Afsarmanesh, H., Ollus, M. (eds.) Proceedings of PRO-VE 2006, pp. 199-210 (2006)

19. Vienne, P., Sourrouille, J.L., Maranzana, M.: Modeling distributed applications for QoS management. In: Gschwind, T., Mascolo, C. (eds.) SEM 2004. LNCS, vol. 3437, pp. 170 184. Springer, Heidelberg (2005)

20. Yang, X., Moore, P., Pu, J.S., Wong, C.B.: A practical methodology for realizing product service systems for consumer products. Computers and Industrial Engineering 56, 224-235 (2009) 